\title{
Degradation of Bisphenol-A: A Contaminant of Emerging Concern Using Catalytic Ozonation By Activated Carbon Impregnated Nanocomposite- Bimetallic Catalyst
}

\section{Hariprasad Pokkiladathu}

Bharathiar University

\section{Salman Farissi}

Central University of Kerala

\section{Anbazhagi Sakkarai}

Central University of Kerala

Muthukumar Muthuchamy ( $\square$ mmuthukumar@cukerala.ac.in )

Central University of Kerala https://orcid.org/0000-0002-8854-0794

\section{Research Article}

Keywords: Bisphenol A, Bimetallic catalyst, Characterization, Contaminants, Degradation, Ozonation, TOC

Posted Date: October 21st, 2021

DOl: https://doi.org/10.21203/rs.3.rs-931223/v1

License: (1) (1) This work is licensed under a Creative Commons Attribution 4.0 International License.

Read Full License

Version of Record: A version of this preprint was published at Environmental Science and Pollution Research on March 15th, 2022. See the published version at https://doi.org/10.1007/s11356-022-195133. 


\section{Abstract}

Rampant water pollution events and rising water demand caused by exponential population growth and depleting freshwater resources speak of an impending water crisis. The inability of conventional wastewater treatment systems to remove Contaminants of Emerging Concern (CEC) such as Bisphenol-A (BPA) beckons for new and efficient technologies to remove them from wastewater and water sources. Advanced oxidation processes such as ozonation are primarily known for their capability to oxidize and degrade organic entities in water but optimum mineralization levels were hard to achieve. In this study, we synthesized an activated carbon impregnated nanocomposite-bimetallic catalyst $\left(\mathrm{AC} / \mathrm{CeO}_{2} / \mathrm{ZnO}\right)$ and used it along with ozonation to remove BPA from water. The catalyst was characterized using BET, XRD, FESEM, Raman spectra, and DLS studies. Catalytic ozonation achieved TOC removal $25 \%$ higher than non-catalytic ozonation process. The degradation pathway of BPA was proposed using LC-MS/LC-Q-TOF studies that found six main aromatic degradation byproducts. Catalytic ozonation and non-catalytic ozonation followed similar degradation pathways. The formation of persistent aliphatic acidic byproducts in the treated sample made TOC removal above $61 \%$ difficult.

\section{Introduction}

Water pollution is a matter of global concern. Pollution events have aggravated partly due to the ineffectiveness of conventional wastewater treatment plants to remove the rising tide of pollutants. Among them, organic pollutants under the category of Contaminants of Emerging Concern (CECs) are of particular concern due to their ubiquitous nature (Fairbairn et al., 2018).

Bisphenol-A is an endocrine disrupting compound widely used in the production of epoxy resins and polycarbonate plastics. BPA is associated with reproductive system damage in living organisms. Its presence in the environment and water bodies are ubiquitous due to its wide use. Conventional wastewater treatments were unable to remove them efficiently.At present, it is classified under the larger group of CECs. In this context it becomes imperative to find an efficient technology to remove CECs such as BPA from water sources (Fürhacker et al, 2000, Amjad et al, 2020)

Advanced oxidation processes (AOP) attracted specific interest from the scientific community because of their high removal, time efficiencies, manual automation capabilities, and zero residue degradation pathways, reducing the need for post-treatments (Garrido-Cardenas et al., 2020). Ozonation produces $\mathrm{O}_{3-}$ radicals that destroy organic molecules and also disinfects drinking water. However, their use to destroy organic chemical molecules had mixed results (Tizaoui $C$ et al., 2011). The introduction of oxygen molecules and hydrogen peroxide in AOPs enhances organic pollutant degradation due to the in situ hydroxyl radical production (Duarte et al., 2018). In this regard, ozonation might succeed if hydroxyl radicals could be produced in situ.

Nanocatalysts enhance photocatalytic removal of organic pollutants from water and wastewater resources. Heterogeneous catalysts were more efficient than homogeneous catalysts because of the 
larger number of holes; hence lesser activation energy and broader energy bandwidths. Less costly metaloxides as heterogeneous catalysts are preferred for organic pollutant removals than the costly non-metal oxides (Korotcenkov, 2019). Cerium dioxide $\left(\mathrm{CeO}_{2}\right)$ provided better organic pollutant removal rates when used along with Fenton processes. When used with other catalysts, they can produce strong oxidants such as superoxide and hydroxyl radicals. The catalytic activity of $\mathrm{CeO}_{2}$ has a direct correlation with its reducibility and the initiation of oxygen vacancies. According to the literature, the key to increasing the process efficiency of $\mathrm{CeO}_{2}$ based wastewater treatment is to increase the redox reactions at the catalyst surface. In this regard, $\mathrm{CeO}_{2}$ nano-rods were found to have higher surface redox capacity than $\mathrm{CeO}_{2}$ nanocubes due to the former's lesser activation energy requirement for $\mathrm{H}_{2} \mathrm{O}_{2}$ decomposition (Korotcenkov, 2019). Literatures establish $\mathrm{ZnO}$ as an efficient less costly photocatalyst with UV and visible light sources. It has been successfully used to remove organic dyes, persistent organic pollutants and Phenolic compounds from water and wastewater (Lee et al., 2016). ZnO's efficiency as photo and sonocatalyst is due to its capability to produce higher concentrations of reactive oxygen species such as superoxide radicals and hydroxyl radicals which helps in oxidizing the pollutants in water and wastewater sources (Lee et al., 2016, Khataee et al., 2015). For the use of nanocatalysts in water and wastewater treatments, substrates are needed. Substrates that provide adequate surface and optimal binding for robust structure and stability is preferred. Activated carbon (AC) is found to be a suitable substrate in many nanocatalyst applications. It is cheap and biodegradable. Its production from wood, sugarcane bagasse and other organic materials makes it environment friendly (Dias et al., 2007, Hernandez-Leal et al.,2011).

AC produced from sugarcane bagasse was usedas the substrate for $\mathrm{CeO}_{2}$ and $\mathrm{ZnOnanocatalysts.} \mathrm{The}$ nanocomposite-bimetallic catalyst thus synthesized was used for producing hydroxyl and superoxide radicals from the ozonation process to degrade Bisphenol A- a contaminant of emerging concern (CEC). Bisphenol-A wasused as the model compound for assessing the efficacy of catalytic ozonation for CEC removal from water. The structure, stability and morphology of the synthesized catalyst were studied using techniques such as X-Ray Diffraction (XRD), Field Emission Scanning Electron Microscope (FESEM) and others. The degradation efficiency and the mechanism of degradation were analysed using High Performance Liquid Chromatography (HPLC) and Liquid Chromatography (LC)-Mass Spectrometry (MS) studies.

\section{Materials And Methods}

\section{Preparation of activated carbon supported nano-composite bimetallic catalyst (ANBCC)}

$100 \mathrm{~g}$ of dried crushed sugarcane bagasse samples were physically activated in a muffle furnace (Genuine Equipment Manufacture, India), at $500^{\circ} \mathrm{C}$ for $1 \mathrm{~h}$. Then, the sample was weighed and soaked in $1 \mathrm{M} \mathrm{KOH}$ in 1:1 ratio for $24 \mathrm{~h}$. The product obtained was chemically activated at $300^{\circ} \mathrm{C}$ for $2 \mathrm{~h}$ with a muffle furnace. Free alkalis of the carbonized material were removed by washing it with double distilled water. 
Then, dried at $100 \pm 5^{\circ} \mathrm{C}$ for $2 \mathrm{~h}$ and weighed to calculate the yield of activated carbon. The activated carbon product obtained was used to make the nano-composite bimetallic catalyst.

Metaloxidessuch as Zinc Oxide ( $\mathrm{ZnO})$ and Cerium(IV) oxide $\left(\mathrm{CeO}_{2}\right)$ were bought from LobaChemie (Mumbai, India) and prepared the nano-metal oxides with Ball milling process (Star Trace Pvt. Ltd, India). Bulk metal oxides were exposed to 200 RPM for $15 \mathrm{~h}$ with $8 \mathrm{~mm}$ stainless steel balls at a ratio of 20:1 (Ball:Powder) in a horizontal ball mill. Activated carbon and nano metal oxides in the ratio of 2:1 were dispersed in $0.5 \mathrm{M} \mathrm{HClfor} 6 \mathrm{~h}$ and evaporated to dryness in an oven for the formation of slurries. The composite material products were washed with MilliQ water and then dried in a hot air oven (Genuine Equipment Manufacture, India) at $100^{\circ} \mathrm{C}$ for $24 \mathrm{~h}$. They were grinded into powder using mortar and pestle (Olusholaet al., 2013). The surface area of the catalysts wereanalysed by BET method.50 mg of BPA (Merck, Bangalore, India) was weighed and dissolved in $1000 \mathrm{ml}$ double distilled water and $100 \mathrm{ml}$ stock solution was made. Then the stock solution was diluted to $1000 \mathrm{ml}$ in standard flask with double distilled water to make working standard of 5mg/L BPA.

\section{Characterization of activated carbon and bimetallic catalysts}

The synthesized nanoparticles, activated carbon, nano-composite bimetallic catalyst, were subjected to XRay Diffraction (XRD), so as to understand to what extent the ball milling has influenced the structure. Xray diffraction patterns were recorded using computer controlled XRD units (PANalytical X-ray diffractometer- XPERT PRO, Netherland). The XRD patterns were recorded between $2 \theta$ angles, $20-70^{\circ}$ at a scan rate of $2 \%$ min from which d-spacings were calculated. The resulting analysis was described graphically as a set of peaks with intensity on the $Y$-axis and goniometer angle on the $X$-axis. If the sample is powdered, it provides, theoretically, all possible orientations of the crystal lattice, the goniometer provides a variety of angles of incidence, and the detector measures the intensity of the diffracted beam. The exact angle and intensity of a set of peaks is unique to the crystal structure being examined. A comparison with patron tables, such as Joint Committee on Powder Diffraction Standards (JCPDS) spectra published by the American Society for Testing and Materials, provides valuable information about composition of the powder (Frank Settle, 1997). The crystallite sizes were calculated from the X-ray broadening technique as per the Scherrerformula on the best resolved diffraction peak (Cullity, 1978):

$\mathrm{D}=0.94 \lambda /(\beta 2$ sample $-\beta 2 \mathrm{ref}) 1 / 2 \cos \theta$

Where, $D$ is the crystallite size diameter $(\mathrm{nm}), \lambda=1.54 \AA, \beta$ is the full width at half maximum (FWHM) of a diffraction peak and $\beta$ ref corresponds to the instrumental FWHM.

Scanning electron micrographs were taken using a field emission scanning electron microscopy (FESEM) (JEOL, JSM- 5600, England) attached Energy dispersive X-ray (EDX) at $10 \mathrm{kV}$. The sample powders were deposited on a carbon tape before mounting on a sample holder after sputter coating gold for conduction. 
Raman spectra using Horiba Jobin Raman spectrometer, Japan reflection mode, wavelength of $532 \mathrm{~nm}$, $2 \mathrm{~mW}$ spectrometer coupled to an Olympus metallographic microscope was used. A $0.1 \mathrm{~g}$ of the sample placed on a sample holder and spectra were recorded in the $100-1000 \mathrm{~cm}^{-1}$.

\section{Experimental setup for ozonation process}

The experimental set up consists of oxygen concentrator ( $\mathrm{Sim} \mathrm{O}_{2}$, Italy),ozone generator (Ozonetek Ltd, Chennai, India)and ozonation chamber. Ozone was generated by the oxygen flow (99.7\%) from the oxygen concentrator into the ozone generator at a flow rate of $1.5 \mathrm{~L} / \mathrm{min}$. The reactor (ozonation chamber) had a glass column of $45 \mathrm{~cm}$ height, an inner diameter of $6.5 \mathrm{~cm}$ with an outlet at the bottom through which the sample was collected after treatment. The teflon tube was used for connecting the ozone generator to the ozone reaction chamber and outlet port. One inlet and one outlet were present at the top of the reactor. During the treatment, the ozone-oxygen mixture was bubbled through diffuser and ozone was sent to thermal vent before sending it outside. The volume of sample taken for each experiment was $1000 \mathrm{~mL}$.Initial ozone concentration of $4 \mathrm{~g} / \mathrm{h}$ was maintained throughout the experiment.

For all the experiments, the initial $\mathrm{pH}$ was adjusted through addition of $0.1 \mathrm{~N} \mathrm{NaOH}$ or $0.1 \mathrm{~N} \mathrm{HCl}$ solutions with the help of pH meter (Susima AP-1 Plus, Chennai, India).The reactor was placed on a magnetic stirring block (Superfit, Coimbatore, India) in order to keep its contents well mixed during the experiment. The schematic diagram of the ozonation process is shown in Fig. 1After each run, the reactor was washed with distilled water. During the ozonation processes, $20 \mathrm{~mL}$ of sample was withdrawn each time at a definite time interval and processed for separation using a centrifuge at $5000 \mathrm{rpm}$ for $15 \mathrm{~min}$. $\mathrm{pH}$ of the sample was analyzed before and after treatment. The supernatant of sample was filtered with Millipore filter $(0.20 \mu \mathrm{m})$ and then analyzed for BPA removal, HPLC, TOC, LC-MS and LC-Q-TOF.

\section{Degradation studies}

TOC was estimated using the procedures adopted from APHA 5310B (APHA 2016). FTIR absorption spectra of the air dry crystal before and after treatment were analyzed using FT-IR spectrometer (Thermo scientific, Model-Nicolet 10, USA).15mg of sample was dispersed in 200mg of spectroscopic grade $\mathrm{KBr}$ to record in the range between $4000 \mathrm{~cm}^{-1}$ and $400 \mathrm{~cm}^{-1}$. The spectra were recorded on $\mathrm{KBr}$ discs of the dried sorbent. Before each measurement, the instrument was run to establish the background, which was then automatically subtracted from the sample spectrum.HPLC studies were conducted using procedures adopted from Romani et. al, (1994). LC-MS/LC-Q-TOF studies were conducted using procedures adopted from ThalamadaiKaruppiah and Bhaskar Raju (2009).

\section{Results And Discussion}

\section{Characterization studies}

Characterization of the nanoparticles and the nano-composite bimetallic catalyst were done by the analysis of the catalyst yield, and using BET surface area, XRD, FESEM, Raman Spectra, and DLS studies. 
Table 1. shows the yield of nanoparticles after $15 \mathrm{~h}$ of ball milling. The yield of $\mathrm{CeO}_{2}$ was $17.3 \mathrm{~g}$. Yield of $\mathrm{ZnO}$ nanoparticle was $17.7 \mathrm{~g}$. The size of nanoparticles was found to be $24.89 \mathrm{~nm}$ for $\mathrm{CeO}_{2}$ and $15.9 \mathrm{~nm}$ for $\mathrm{ZnO}$ based on the analysis of DLS and XRD. The efficiencyof the catalytic ozonation process depends to a large degree on the catalyst and its surface areaproperties. Thus the surface area is a crucial factor in catalytic ozonation. The results of surface area analysis areshown in Table 2. It shows that nanocomposite bimetallic catalyst was having a surface area of $32.39 \mathrm{~m}^{2} / \mathrm{g}$ (BET surface area). The pore size was $88^{\circ} \mathrm{A}$ and Pore volume was greater than $0.071579 \mathrm{~cm}^{3} / \mathrm{g}$.

XRD pattern of the $\mathrm{CeO}_{2}$ nano-particlessynthesized by ball milling process is shown in Fig. 2. All peaks in the XRD spectra were indexed as (JCPDS-34-0394) of $\mathrm{CeO}_{2}$. From the analysis of XRD pattern, peak intensity, position and full-width at half-maximum (FWHM) data were determined. The diffraction peaks located at $28.54^{0}, 33.08^{0}, 47.48^{0}, 56.34^{0}, 59.09^{\circ}$ and $69.42^{\circ}$ belongs to $\mathrm{CeO}_{2}$. This confirmed the synthesized nanoparticle's purity. There were no other characteristic peaks other than $\mathrm{CeO}_{2}$ peaks. The synthesized $\mathrm{CeO}_{2}$ nanoparticle diameter was calculated using Debye-Scherrer formula (Desai et al., 2020). The average particle size of the sample was found to be $24.89 \mathrm{~nm}$.

Figure 2, shows the XRD patterns of the individual metal oxides, $\mathrm{AC}$ and the nanocomposite bimetallic catalyst. The diffraction peaks at $28.54^{\circ}, 47.48^{\circ}, 56.34^{\circ}, 59.09^{\circ}$ and $69.42^{\circ}$ belongs to $\mathrm{CeO}_{2}$ and diffraction peaks located at $31.77^{\circ}, 34.43^{\circ}, 47.55^{\circ}$ and $69.68^{\circ}$ were related to $\mathrm{ZnO}$ nanoparticles (JCPDS: 65-3411) (Shi et al., 2014). The peaks at $24^{0}$ and $42^{0}$ correspond to activated carbon (Song et al., 2017). The composite peaks found in the XRD analysis mostly corresponds to $\mathrm{CeO}_{2}$. The X-ray diffraction patterns of the activated carbon structure showed diffused peaks at $24^{0}$ and $42^{0}$. They appeared at narrow angles as fingerprint peaks. The AC structures were highly amorphous in nature and they had heterogeneous surface (Danish et al., 2011).

The structural characterization of pure $\mathrm{CeO}_{2}$ nanoparticle was done using FESEM. Figure 3 shows the FESEM-Image of $\mathrm{CeO}_{2}, \mathrm{ZnO}, \mathrm{AC}$ nanoparticles and $\mathrm{AC} / \mathrm{CeO}_{2} / \mathrm{ZnOnano-composite} \mathrm{bimetallic} \mathrm{catalyst.} \mathrm{The}$ morphological studies showed that $\mathrm{CeO}_{2}$ nanoparticles had uniform agglomerated nanosphere structure. The morphology of the synthesized $\mathrm{ZnO}$ nanoparticle was in the form of triangle shaped nano rods like triangle prism and the pores had been created on activated carbon during the activation process of carbon. The pores were partially opened due to an increase in activation temperature from $500^{\circ} \mathrm{C}$ to $600^{\circ} \mathrm{C}$. $\mathrm{CeO}_{2}$ nanoparticles were evenly distributed and $\mathrm{ZnO}$ was evenly impregnated on activated carbon.

Figure 4 (a) shows the Raman Spectra of $\mathrm{AC} / \mathrm{CeO}_{2} / \mathrm{ZnO}$ nanocomposites. The Raman spectrum of the nanocomposites exhibited an intense band at $453.79 \mathrm{~cm}^{-1}$, which is attributed to a symmetrical stretching mode of the $\mathrm{CeO}_{2}$ (Maensiri et al., 2014; Reddy et al., 2007). The peaks for ZnO nanoparticles at $95.71 \mathrm{~cm}^{-1}$ and $585.49 \mathrm{~cm}^{-1}$ were assigned to the low, high longitudinal optical phonon peak of the ZnO nanoparticles (Du et al., 2005; Song et al., 2019; Damen et al., 1966). The obtained spectra also showed the presence of the band near $1583.56 \mathrm{~cm}^{-1}$ (G band) typical of more organized graphitic materials and 
band at $1349.55 \mathrm{~cm}^{-1}$ ( $\mathrm{D}$ band) suggested the presence of more defective amorphous carbon structures. The peaks at $1593.55 \mathrm{~cm}^{-1}$ and $132.71 \mathrm{~cm}^{-1}$ were typical of activated carbon (Nakamizo et al., 1974).

Particle size has a direct influence on material properties such as reactivity and dissolution rate of catalysts. Analyzing the particle size of the catalyst will fetch information on the interaction between catalyst and ozone. Figure 4 (b), represents the graphical representation of Dynamic Light Scattering result. The Particle size of the nano-composite bimetallic catalyst was found to be $453.3 \mathrm{~d} . \mathrm{nm}$.

\section{Degradation studies}

Catalytic ozonation shows great advantages in removing the refractory organics present in water, and is expected to become a powerful and valuable technology in water treatment.Themechanism of catalytic ozonation is based on ozone decomposition reactions followed by the generation of hydroxyl radicals. The metal ions accelerate the decomposition of ozone to produce the $\cdot \mathrm{O}_{2}$, and then electron of $\cdot \mathrm{O}_{2}$ transfers to $\mathrm{O}_{3}$. This is followed by the formation of $\bullet_{3}$, and $\cdot \mathrm{OH}$. Figure 5 represents the impact of $\mathrm{pH}$, catalyst dosage and time on catalytic ozonation of BPA and TOC removal. It was found that when $\mathrm{pH}$ increases from 6 to 8 at catalyst dosage of $500 \mu \mathrm{g} / \mathrm{L}$ and ozone rate $4 \mathrm{~g} / \mathrm{h}$, the trend of TOC removal in oxidation process increased. When $\mathrm{pH}$ was 8 , maximum TOC removal was observed within 35 minutes. Increasing the $\mathrm{pH}$ from 8 to 10 showed a decreasing pattern in TOC removal. The possible reason for showing maximum removal at $\mathrm{pH} 8$ was because of the generation of more hydroxyl radicals that randomly reacted with BPA, and a decrease in TOC removal was due to clogging of hydroxyl radicals at higher $\mathrm{pH}$ (Wang et al., 2019).

Catalyst dosage is a significant aspect in catalytic ozonation. The catalyst surface and type of catalyst also plays a key role in heterogeneous catalytic ozonation. The catalyst dosage selected for the study was in the range of $250 \mu \mathrm{g} / \mathrm{L}$ to $750 \mu \mathrm{g} / \mathrm{L}$. When the catalyst dosage increased from $250 \mu \mathrm{g} / \mathrm{L}$ to $500 \mu \mathrm{g} / \mathrm{L}$ at $\mathrm{pH} 8,60$ minutes and ozone rate $4 \mathrm{~g} / \mathrm{h}$, the TOC removal increased. Further increase in catalyst dosage did not show competent increase in TOC removal. At 500 $\mathrm{g} / \mathrm{L}$ catalyst dosage, $61 \%$ TOC removal was achieved within a time of 60 minutes.

At $\mathrm{pH} 8$, Ozone rate $4 \mathrm{~g} / \mathrm{h}$ and $500 \mu \mathrm{g} / \mathrm{L}$ of catalyst dosage, maximum TOC removal was achieved within 60 minutes. This was because maximum ozone molecules reacted with the catalyst surface within this time. The Ozone molecules decomposed to hydroxyl radicals at the catalyst surface and reacted with the BPA.

\section{Comparison of catalytic ozonation and non-catalytic ozonation}

From Fig. 6, it is evident that the TOC removal efficiency of catalytic ozonation is high compared to noncatalytic ozonation. Non-catalytic ozonation achieved only $36 \%$ of TOC removal, while catalytic ozonation achieved $61 \%$ TOC removal. The increased efficiency was due to the formation of hydroxyl radicals by ozone decomposition on the surface of the nano-composite bimetallic catalyst. The available 
surface area of $\mathrm{AC} / \mathrm{CeO}_{2} / \mathrm{ZnO}$ nano-composites prompted minimization of the diffusion limitations allowing the rapid adsorption and desorption of ozone molecules dissolved in water.

Figure 7 shows the FTIR spectra of $\mathrm{AC} / \mathrm{CeO}_{2} / \mathrm{ZnO}$ nano-composite bimetallic catalyst before and after catalytic ozonation. The band due to the stretching frequency of Ce-O is below $785 \mathrm{~cm}^{-1}$ which means that the stretching band at $551.93 \mathrm{~cm}^{-1}$ and $774.23 \mathrm{~cm}^{-1}$ belongs to Ce-O stretch. The "scissor" bending of $\mathrm{H}-\mathrm{O}-\mathrm{H}$ broad absorption band located at $1596.26 \mathrm{~cm}^{-1}$ is associated with water (Jiang et al., 2016). The absorption band located around $3777.69 \mathrm{~cm}^{-1}$ corresponds to the $\mathrm{O}-\mathrm{H}$ stretching vibration of residual water and hydroxyl groups. The stretching at $1225.23 \mathrm{~cm}^{-1}$ can be attributed to the $\mathrm{O}-\mathrm{H}$ vibration in absorbed water on the sample surface. The stretching frequency of Ce-O can be seen at $767.83 \mathrm{~cm}^{-}$ ${ }^{1}$ also. The FT-IR peaks at $1589.98 \mathrm{~cm}^{-1}, 1231.63 \mathrm{~cm}^{-1}, 1039.71 \mathrm{~cm}^{-1}, 1064 \mathrm{~cm}^{-1}, 952 \mathrm{~cm}^{-1}$ and $767.83 \mathrm{~cm}^{-1}$ were similar to those of commercial $\mathrm{CeO}_{2}$ powders (Shen et al., 2013) and $\mathrm{CeO}_{2}$ nanoparticles (Phoka et al., 2009). The band at $767.83 \mathrm{~cm}^{-1}$ corresponds to (Ce-O) metal-oxygen bond (Kumar et al., 2013). The small and weak stretching at 1210.83 is ascribed to $\mathrm{C}-\mathrm{O}$ in carboxylic acid. The weak stretching at 1596.26 is assigned to carbonyl $C=0$ present in esters, aldehydes, ketonic groups and acetyl derivatives. The small stretching at 2362.32 belongs to weak $\mathrm{C} \equiv \mathrm{C}$ band of alkynes (Rother et al, 2016).

In the FTIR spectrum of nanocomposites, the absorption at $1601.28 \mathrm{~cm}^{-1}$ was assigned to the $\mathrm{C}=\mathrm{C}$ stretching of activated carbon (Allwaret al., 2012; Rother et al., 2016). The absorption curve at 1001.97 $\mathrm{cm}^{-1}$ belonged to the asymmetry vibration of $Z \mathrm{n}-0$. The absorption curve at $812.72 \mathrm{~cm}^{-1}$ was ascribed to the $\mathrm{Zn}-\mathrm{O}$ stretching of $\mathrm{ZnO}$ (Xiong et al., 2006). The FTIR spectra confirmed the presence of nanocomposites and the absence of impurities in both the precursors and the prepared composite materials.

The FTIR spectra of $\mathrm{AC} / \mathrm{CeO}_{2} / \mathrm{ZnO}$ nanocomposite obtained after the catalytic ozonation process confirmed the degradation of BPA and the formation of intermediates. The $\mathrm{O}-\mathrm{H}$ stretching vibration at $3443.35 \mathrm{~cm}^{-1}$ was attributed to the phenolic group. The stretching between the ranges of wave numbers $2800-3200 \mathrm{~cm}^{-1}$ were attributed to $\mathrm{C}-\mathrm{H}$ stretching. Thepeaks at $1476.45 \mathrm{~cm}^{-1}$ to $1670.81 \mathrm{~cm}^{-}$ ${ }^{1}$ wave numbers represented C-O andC-OH bonds of carboxylic groups (Ren et al., 2012). The peak at $1013.10 \mathrm{~cm}^{-1}$ is ascribed to the shift of skeletal vibration ofC $\left(\mathrm{CH}_{3}\right)_{2}$ group of BPA (Sahre et al., 2006). The peaks with wave numbers less than $1000 \mathrm{~cm}^{-1}$ represents the para-di-substituted and monosubstituted and/or ortho-di-substituted compounds (Jang andWilkie, 2004). There was also an indication of the formation of polyphenols such as resorcinol (Jyoti et al., 2016). From the above observations, it can be inferred that $\mathrm{AC} / \mathrm{CeO}_{2} / \mathrm{ZnO}$ nanocomposites facilitated the production of $\cdot \mathrm{OH}$ and degradation of BPA.

The removal of BPA was analysed using HPLC and it is presented in the Fig. 8. At 60 minutes of catalytic ozonation, BPA concentration decreased about $97 \%$. During catalytic ozonation, the degradation of BPA 
produced several low molecular weight organic acids which lead to the decrease in the initial solution $\mathrm{pH}$. In order to better understand the BPA degradation during catalytic ozonation, $\mathrm{pH}$ of the solution after treatment was estimated with respect to different initial $\mathrm{pH}$. The initial $\mathrm{pH}$ of the solutions were $5,6,8,9$, and 11 and after treatment the $\mathrm{pH}$ of the solutions were 4.81, 4.12, 5.26, 7.57 and 10.17 respectively. The incomplete removal of TOC indicated the possibility of theformation of intermediates.

LC-MS/LC-Q-TOF analysis was performed by comparing the chromatogram of BPA with those of the aliquots taken at different ozonation times. All samples were subjected to similar derivatisation procedure as mentioned inThalamadaiKaruppiah and Bhaskar Raju (2009). Figure 9(C) shows the LCMS/LC-Q-TOF chromatogram of degradation byproducts. Identification of degradation byproducts was carried out based on fragmentation patterns in the mass spectrum and/or by comparing the mass spectrum with the library available in the instrument database. The proposed five aromatic degradation byproducts are given in Table 3. Researchers had reported the formation of hydroxylated BPA byproducts such as monohydroxylated BPA, dihydroxylated BPA and their quinones. The phenyl moiety based compounds such as p-isopropenyl and p-isopropyl phenol, p-hydroxyacetophenone, etc would have formed(Katsumata et al., 2004; Poerschmann et al., 2010; Olmez-hanci et al., 2013). Acidic compounds (responsible for $\mathrm{pH}$ decrease) such as formic, acetic, oxalic, succinic and fumaric acids were also reported (Katsumata et al., 2004; Olmez et al., 2015). Other studies (Poerschmann et al.,2010; Olmez et al.,2015) pointed to the formation of coupling byproducts with higher molecular weight than BPA.

The proposed fragmentation pathway of BPA by catalytic ozonation is displayed in Fig. 9. The $\cdot \mathrm{OH}$ radicals ruptured the BPA mainly through two attack sites which were the bond that held the two aromatic rings together and aromatic ring itself. The $\cdot \mathrm{OH}$ radicals attacked the methyl bond between the two aromatic rings of BPA and demethylation occurred by hydrogenation and dehydrogenation. The $\cdot \mathrm{OH}$ radicals also attacked aromatic ring structure breaking it through hydroxylation and dehydroxylation. Once the ring structures were broken further rupture of the ring structure and hydrocarbon bonds occurred through the same oxidation and reduction reactions.

\section{Conclusion}

In this study, a novel activated carbon supported nano-composite bimetallic catalyst $\left(\mathrm{AC} / \mathrm{CeO}_{2} / \mathrm{ZnO}\right)$ was prepared by wetness impregnation method for the removal of Bisphenol A from water sources. The presence of $\mathrm{AC}, \mathrm{CeO}_{2}$, and $\mathrm{ZnO}$ in nano bimetallic catalyst was confirmed by yield studies, $\mathrm{BET}$, XRD, FESEM, Raman Spectra, and DLS. The specific surface area and pore size distribution of $\mathrm{AC} / \mathrm{CeO}_{2} / \mathrm{ZnO}$ has played a significant role in catalytic ozonation of BPA. In the alkaline pH condition, ozone decomposition rate increases in water and the half life of ozone in water is short thus the $\cdot \mathrm{OH}$ radical dominate the system as reaction intermediate. Therefore, degradation of BPA occurs due to $\cdot \mathrm{OH}$ radicals produced on the surface of nano-composite bimetallic catalyst not by ozone. $\mathrm{pH} 8$, catalyst dosage of $500 \mu \mathrm{g} / \mathrm{L}$ and treatment time of 60 minutes was found to be the optimal conditions for maximum TOC removal (61\%) achieved. There was $25 \%$ higher TOC removal efficiency for catalytic ozonation compared to non-catalytic ozonation. The FTIR studies of $\mathrm{AC} / \mathrm{CeO}_{2} / \mathrm{ZnOnano-composite} \mathrm{bimetallic} \mathrm{catalyst} \mathrm{found}$ 
that degradation of BPA is due to catalytic ozonation and not due to adsorption. The $\mathrm{pH}$ changes noticed after catalytic ozonation is due to organic acids formed when BPA was oxidized by $\cdot \mathrm{OH}$. LC-Q-TOF analysis found five main aromatic degradation byproducts. They were Hydroquinone, 4Hydroxyacetophenone, 2-(2-(4- Hydroxyphenyl)propan- 2-yl)succinaldehyde, 2-(1-(4- Hydroxyphenyl)vinyl)pent-2-enal, 3-Formyl-4-(4- hydroxyphenyl)-4- methylpent-2-enoic acid. Future studies would concentrate on finding other catalysts that could achieve higher TOC removal and mineralization. Wider applications of the process require life cycle and cost assessments in actual wastewater and natural water conditions.

\section{Declarations}

\section{Data availability}

Not available.

\section{Funding}

The authors declare that they have not received any funding for conducting the research.

\section{Contributions}

HPdid the experimental analysis, conceptualization and preparation of manuscript. SFdidthe data curation, validation and preparation of manuscript. SA did the interpretation of results and editing of manuscript. MM supervised, reviewed and edited the manuscript and gave the overall guidance.

\section{Ethics declaration}

Ethics and consent to participate

Not Applicable.

\section{Consent for publication}

Not applicable.

\section{Competing interests}

The authors declare that they have no known financial or non-financial competing interests.

\section{Rights and permissions}

Not applicable

\section{References}


1. Allwar, A. (2012). Characteristics of pore structures and surface chemistry of activated carbons by physisorption, FtirAnd Boehm methods. IOSR J ApplChem, 2(1), 09-15.

2. Amjad, S., Rahman, M. S., \& Pang, M. G. (2020). Role of Antioxidants in Alleviating BisphenolA Toxicity. Biomolecules, 10(8), 1105. https://doi.org/10.3390/biom10081105

3. Damen, T. C., Porto, S. P. S., \& Tell, B. (1966). Raman effect in zinc oxide. Physical Review, 142(2), 570.

4. Danish, M., Hashim, R., Ibrahim, M. M., Rafatullah, M., Ahmad, T., \&Sulaiman, O. (2011). Characterization of Acacia mangium wood based activated carbons prepared in the presence of basic activating agents. BioResources, 6(3), 3019-3033.

5. Desai, Y. P., Jamwal, S., Modiyil, S., Chodankar, S., Sathe, R., \&Kothawale, M. M. (2020, November). Structural and magnetic studies of nanocrystalline Ni-Zn ferrites synthesized by sol-gel method. In AIP Conference Proceedings (Vol. 2265, No. 1, p. 030511). AIP Publishing LLC.

6. Du, Y., Zhang, M. S., Hong, J., Shen, Y., Chen, Q., \& Yin, Z. (2003). Structural and optical properties of nanophase zinc oxide. Applied Physics A, 76(2), 171-176.https://doi.org/10.1007/s003390201404

7. Fürhacker, M., Scharf, S., \& Weber, H. (2000). Bisphenol A: emissions from point sources. Chemosphere, 41(5), 751-756. https://doi.org/10.1016/S0045-6535(99)00466-X

8. Jang, B. N., \&Wilkie, C. A. (2004). A TGA/FTIR and mass spectral study on the thermal degradation of bisphenol A polycarbonate. Polymer Degradation and Stability, 86(3), 419-

430.https://doi.org/10.1016/j.polymdegradstab.2004.05.009

9. Jiang, X., Li, S., Xiang, G., Li, Q., Fan, L., He, L., \&Gu, K. (2016). Determination of the acid values of edible oils via FTIR spectroscopy based on the $\mathrm{OH}$ stretching band. Food chemistry, 212, 585589. https://doi.org/10.1016/j.foodchem.2016.06.035

10. Karuppiah, M. T., \& Raju, G. B. (2009). Anodic degradation of $\mathrm{Cl}$ reactive blue 221 using graphite and IrO2/TaO2/RuO2 coated titanium electrodes. Industrial \& engineering chemistry research, 48(4), 2149-2156. https://doi.org/10.1021/ie801291h

11. Katsumata, H., Kawabe, S., Kaneco, S., Suzuki, T., \&Ohta, K. (2004). Degradation of bisphenol A in water by the photo-Fenton reaction. Journal of Photochemistry and Photobiology A: Chemistry, 162(2-3), 297-305. https://doi.org/10.1016/S1010-6030(03)00374-5

12. Kumar, A., Thota, S., Sivakumar, S., Priya, S., \& Kumar, J. (2013). Sol-gel synthesis and optical behavior of $\mathrm{Mg}-\mathrm{Ce}-\mathrm{O}$ nano-crystallites. Journal of sol-gel science and technology, 68(1), 4653.https://doi.org/10.1007/s10971-013-3132-4

13. Maensiri, S., Labuayai, S., Laokul, P., Klinkaewnarong, J., \&Swatsitang, E. (2014). Structure and optical properties of $\mathrm{CeO} 2$ nanoparticles prepared by using lemongrass plant extract solution. Japanese Journal of Applied Physics, 53(6S), 06JG14.

14. Nakamizo, S., Shimono, K., Kondo, M., \& Ono, H. (1994). Visual directions of two stimuli in Panum's limiting case. Perception, 23(9), 1037-1048. https://doi.org/10.1068/p231037

15. Olmez-Hanci, T., Arslan-Alaton, I., \&Genc, B. (2013). Bisphenol A treatment by the hot persulfate process: oxidation products and acute toxicity. Journal of hazardous materials, 263, 283- 
290. https://doi.org/10.1016/j.jhazmat.2013.01.032

16. Olmez-Hanci, T., Dursun, D., Aydin, E., Arslan-Alaton, I., Girit, B., Mita, L., ... \&Guida, M. (2015). S2082-/UV-C and H2O2/UV-C treatment of Bisphenol A: Assessment of toxicity, estrogenic activity, degradation products and results in real water. Chemosphere, 119, S115-

S123. https://doi.org/10.1016/j.chemosphere.2014.06.020

17. Phoka, S., Laokul, P., Swatsitang, E., Promarak, V., Seraphin, S., \&Maensiri, S. (2009). Synthesis, structural and optical properties of $\mathrm{CeO} 2$ nanoparticles synthesized by a simple polyvinyl pyrrolidone (PVP) solution route. Materials Chemistry and Physics, 115(1), 423-

428.https://doi.org/10.1016/j.matchemphys.2008.12.031

18. Poerschmann, J., Trommler, U., \&Górecki, T. (2010). Aromatic intermediate formation during oxidative degradation of Bisphenol A by homogeneous sub-stoichiometric Fenton reaction. Chemosphere, 79(10), 975-986. https://doi.org/10.1016/j.chemosphere.2010.03.030

19. Reddy, B. M., Rao, K. N., Reddy, G. K., Khan, A., \& Park, S. E. (2007). Structural characterization and oxidehydrogenation activity of $\mathrm{CeO} / \mathrm{Al} 2 \mathrm{O} 3$ and V2O5/CeO2/Al2O3 catalysts. The Journal of Physical Chemistry C, 111(50), 18751-18758.https://doi.org/10.1021/jp076617|

20. Romani, A., Baldi, A., Tattini, M., \&Vincieri, F. F. (1994). Extraction, purification procedures and HPLC-RI analysis of carbohydrates in olive (Oleaeuropaea L.) plants. Chromatographia, 39(1), 35-

39. https://doi.org/10.1007/BF02320455

21. Rother, M., Nussbaumer, M. G., Renggli, K., \&Bruns, N. (2016). Protein cages and synthetic polymers: a fruitful symbiosis for drug delivery applications, bionanotechnology and materials science. Chemical Society Reviews, 45(22), 6213-6249. https://doi.org/10.1039/C6CS00177G

22. Sahre, K., Hoffmann, T., Pospiech, D., Eichhorn, K. J., Fischer, D., \&Voit, B. (2006). Monitoring of the polycondensation reaction of bisphenol $A$ and 4, 4'-dichlorodiphenylsulfone towards polysulfone (PSU) by real-time ATR-FTIR spectroscopy. European polymer journal, 42(10), 22922301. https://doi.org/10.1016/j.eurpolymj.2006.05.025

23. Shen, B., Zhang, X., Ma, H., Yao, Y., \& Liu, T. (2013). A comparative study of Mn/CeO2, Mn/ZrO2 and $\mathrm{Mn} / \mathrm{Ce}-\mathrm{ZrO} 2$ for low temperature selective catalytic reduction of $\mathrm{NO}$ with $\mathrm{NH} 3$ in the presence of SO2 and H2O. Journal of Environmental Sciences, 25(4), 791-800.https://doi.org/10.1016/S10010742(12)60109-0

24. Shi, S., Qu, Y., Ma, F., \& Zhou, J. (2014). Bioremediation of coking wastewater containing carbazole, dibenzofuran and dibenzothiphene by immobilized naphthalene-cultivated Arthrobacter sp. W1 in magnetic gellan gum. Bioresource technology, 166, 7986.https://doi.org/10.1016/j.biortech.2014.05.036

25. SONG, Y., DANG, M., \& WANG, D. (2017). Numerical Simulation of the Benzene Vapor Adsorption onto the Activated Carbon Fixed-bed. Journal of Shenyang Ligong University.

26. Song, Y., Zhang, S., Zhang, C., Yang, Y., \&Lv, K. (2019). Raman spectra and microstructure of zinc oxide irradiated with swift heavy ion. Crystals, 9(8), 395.https://doi.org/10.3390/cryst9080395 
27. Wang, D., Xu, H., Ma, J., Giannakis, S., Lu, X., Chi, H., .. \& Qi, J. (2019). Enhanced mineralization of atrazine by surface induced hydroxyl radicals over light-weight granular mixed-quartz sands with ozone. Water research, 149, 136-148.https://doi.org/10.1016/j.watres.2018.11.002

28. Xiong, G., Pal, U., Serrano, J. G., Ucer, K. B., \& Williams, R. T. (2006). Photoluminesence and FTIR study of ZnO nanoparticles: the impurity and defect perspective. physica status solidi c, 3(10), 35773581. https://doi.org/10.1002/pssc.200672164

\section{Tables}

Table 1

Yield and size of metaloxide nanoparticles prepared by Ball milling process

\begin{tabular}{|lllll|}
\hline Name & $\begin{array}{l}\text { Initial weight } \\
(\mathbf{g})\end{array}$ & $\begin{array}{l}\text { Final weight } \\
(\mathbf{g})\end{array}$ & $\begin{array}{l}\text { Time of Ball milling in } \\
(\mathbf{h})\end{array}$ & $\begin{array}{l}\text { Size of Nano particle } \\
(\mathrm{nm})\end{array}$ \\
\hline $\mathrm{CeO}_{2}$ & 20 & 17.3 & 15 & 24.89 \\
\hline $\mathrm{ZnO}$ & 20 & 17.7 & 15 & 15.9 \\
\hline
\end{tabular}

Table 2

BET Surface area Analysis results of $\mathrm{AC} / \mathrm{CeO}_{2} / \mathrm{ZnO}$ nano-composites bimetallic catalyst

\begin{tabular}{|llll|}
\hline Compounds & BET surface area $\mathrm{m}^{2} / \mathrm{g}$ & Pore Size $(\AA)$ & Pore volume $\mathrm{cm}^{\mathbf{3}} / \mathbf{g}$ \\
\hline $\mathrm{CeO}_{2}$ Nano particle & 29.6833 & 146.8628 & $>0.108984$ \\
\hline $\mathrm{ZnO}$ Nano particle & 6.4496 & 158.0585 & $>0.025485$ \\
\hline $\mathrm{AC} / \mathrm{CeO}_{2} / \mathrm{ZnONanocomposites}$ & 32.3907 & 88.3948 & $>0.071579$ \\
\hline
\end{tabular}

Due to technical limitations, table 3 is only available as a download in the Supplemental Files section.

\section{Figures}




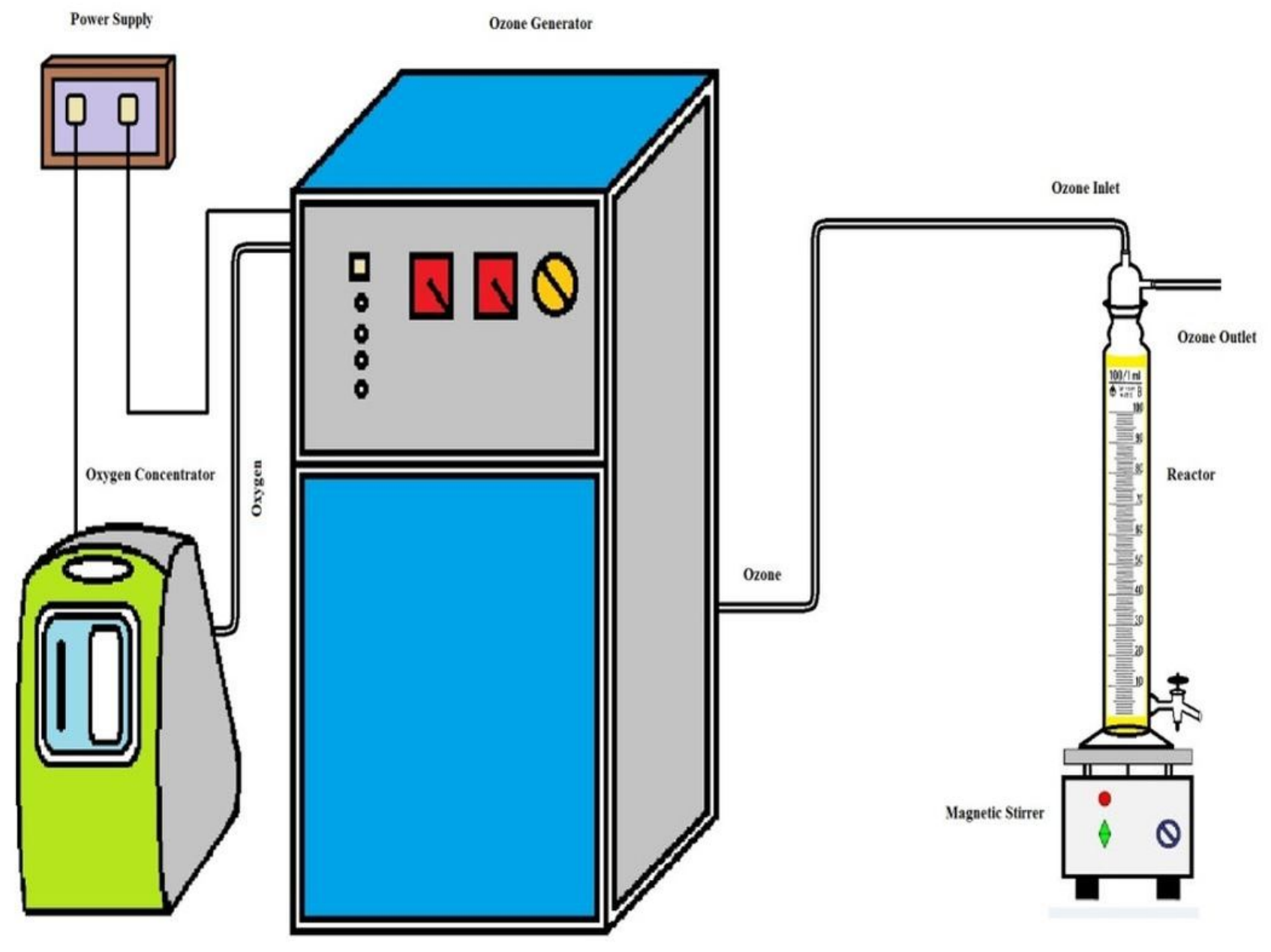

Figure 1

Experiment setup for ozonation processes 


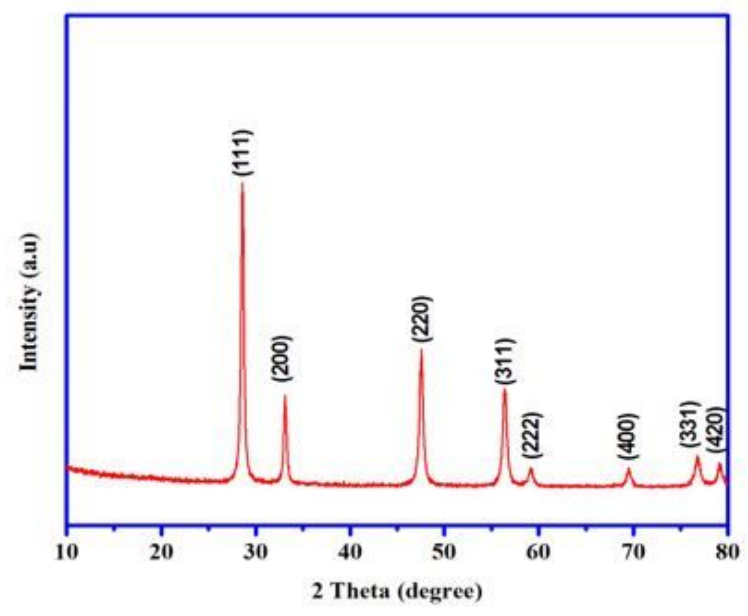

(a)

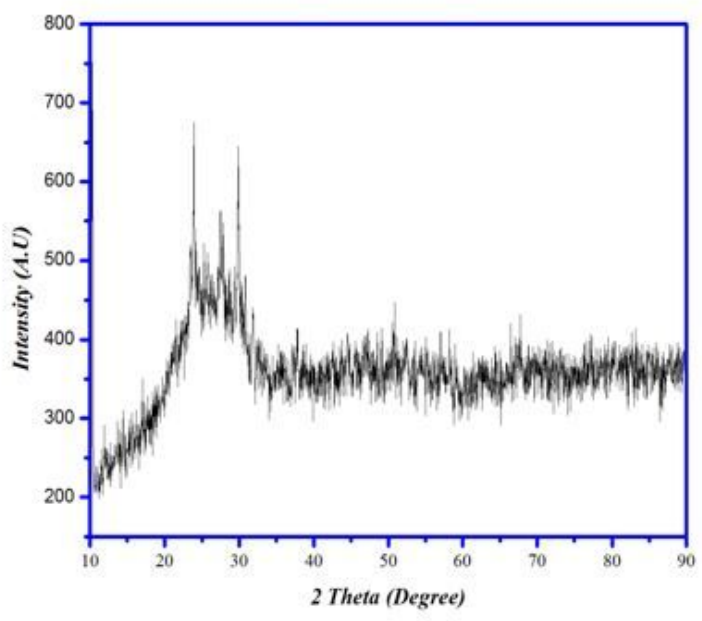

(c)

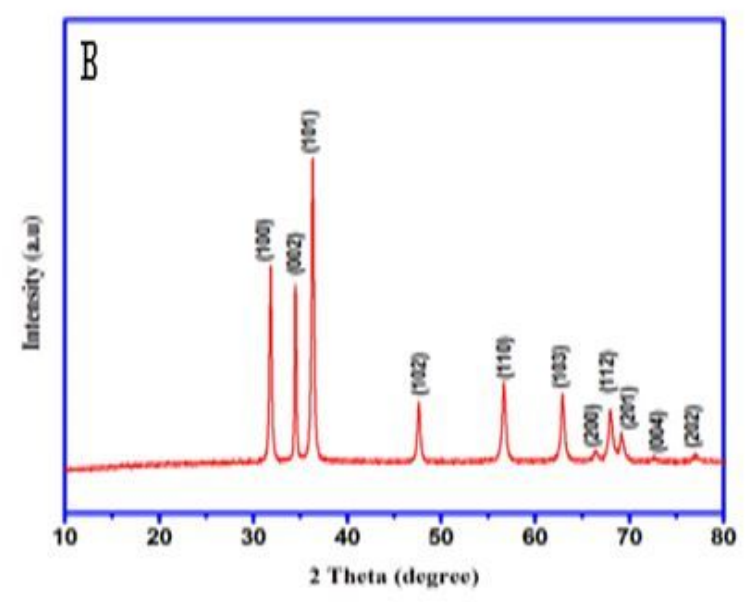

(b)

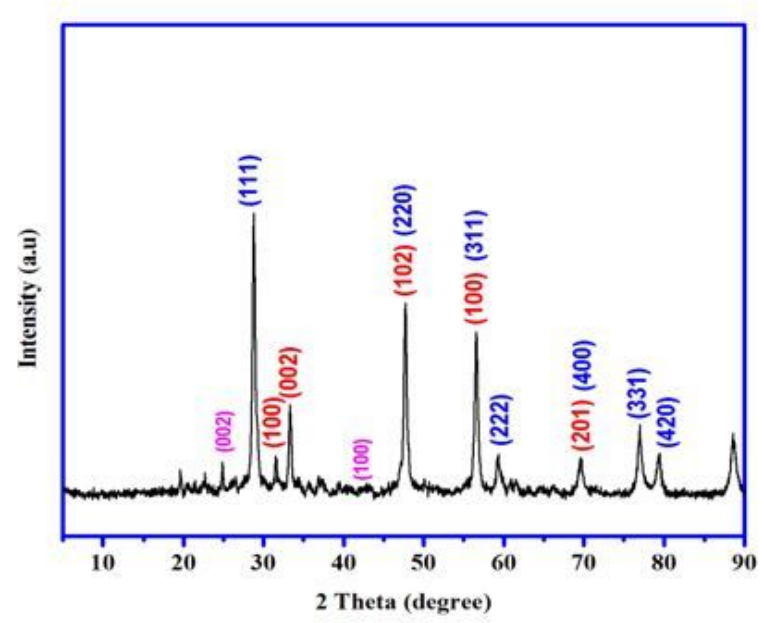

(d)

Figure 2

X-ray diffraction (XRD) Patterns of (a) $\mathrm{CeO}$ (b) ZnO (c) AC and (d) AC/Ce02/ZnO 


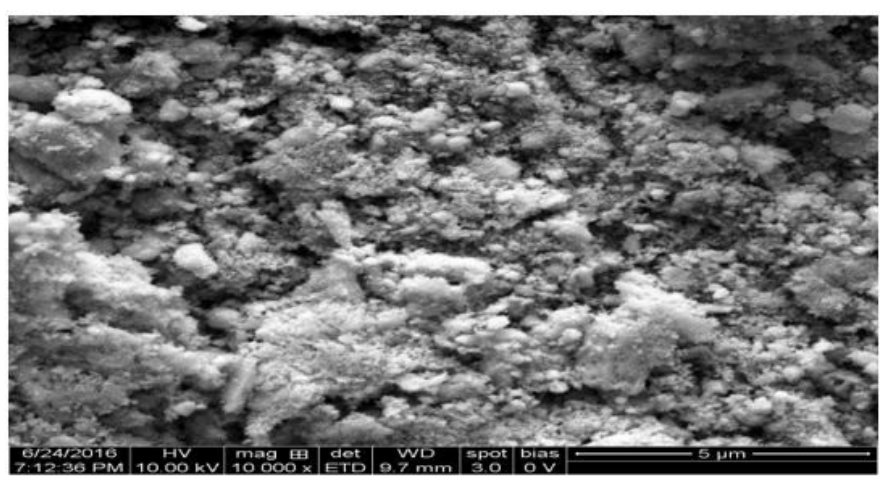

(a)

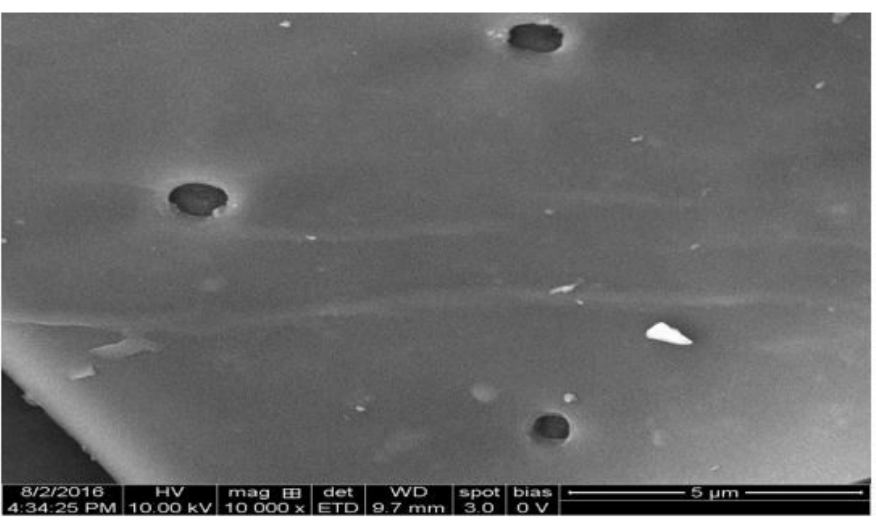

(c)

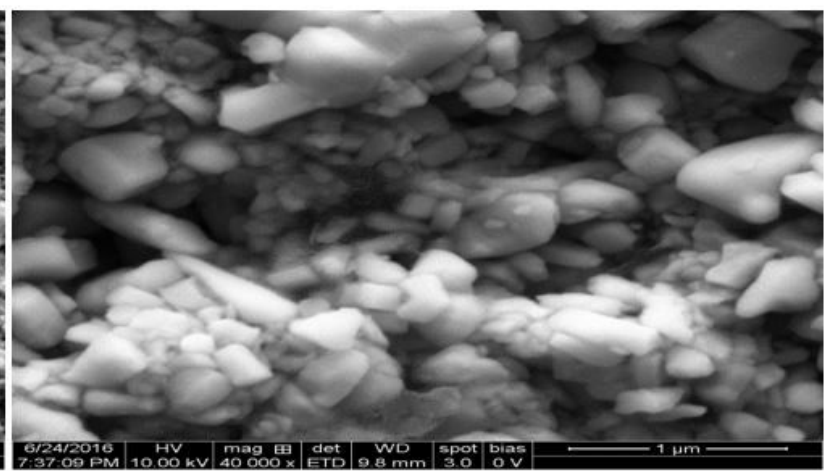

(b)

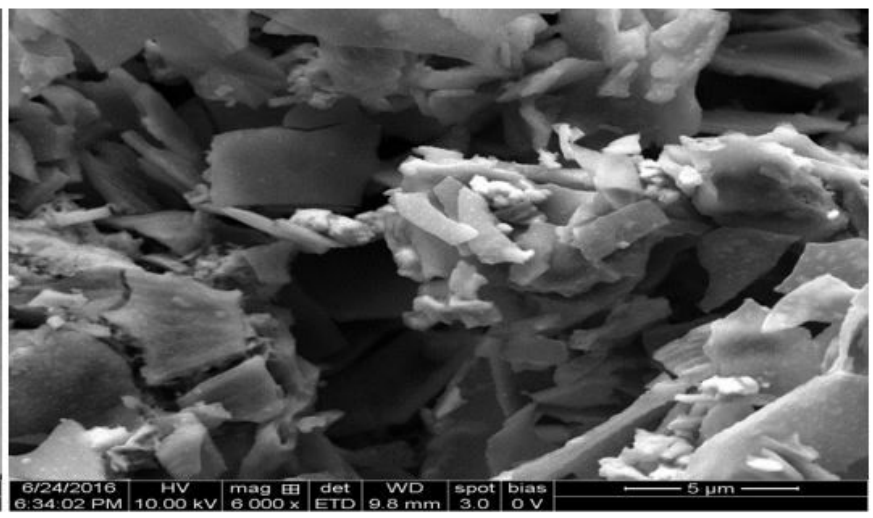

(d)

\section{Figure 3}

FESEM-Images of (a)CeO2 nanoparticles (b) ZnO nano-particles (c) AC nanoparticles and (d) $\mathrm{AC} / \mathrm{CeO} / \mathrm{ZnO}$ Nano-Composite Bimetallic Catalyst 


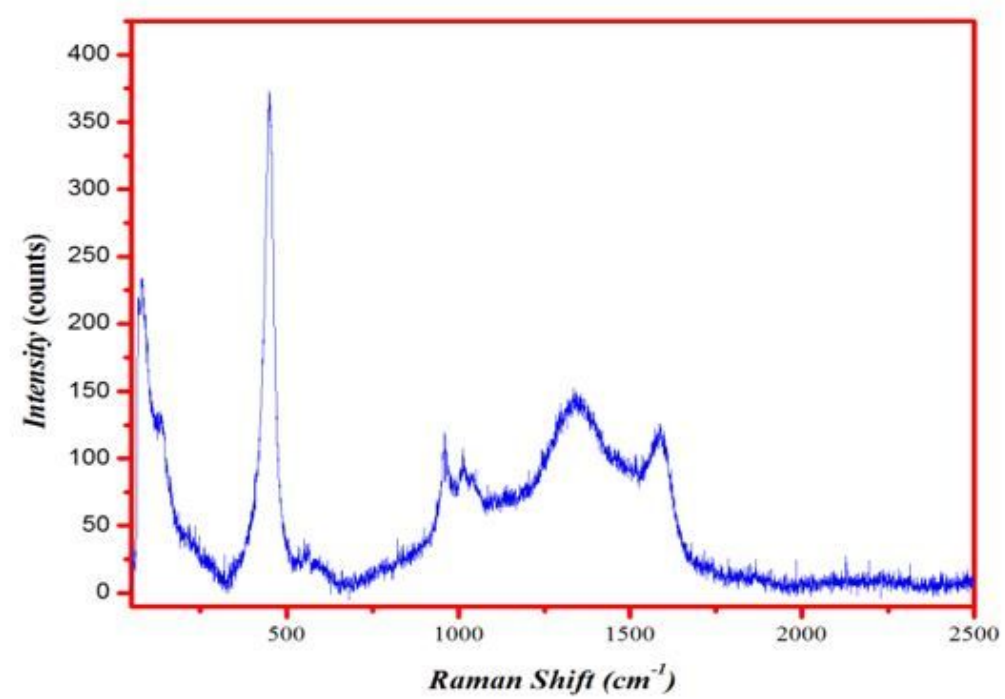

(a)

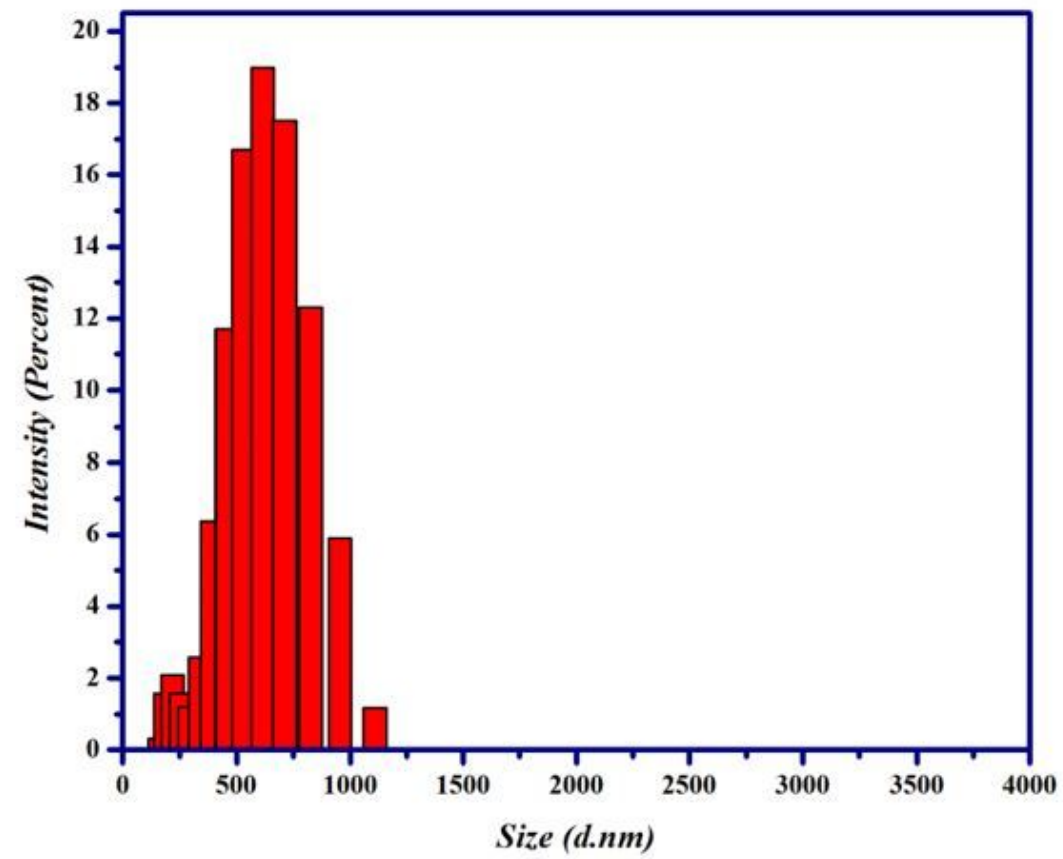

(b)

Figure 4

(a) Raman Spectra of AC/CeO2/ZnO nano-composite bimetallic catalyst (b) DLS image of AC/CeO2/ZnO nano-composite bimetallic catalyst 


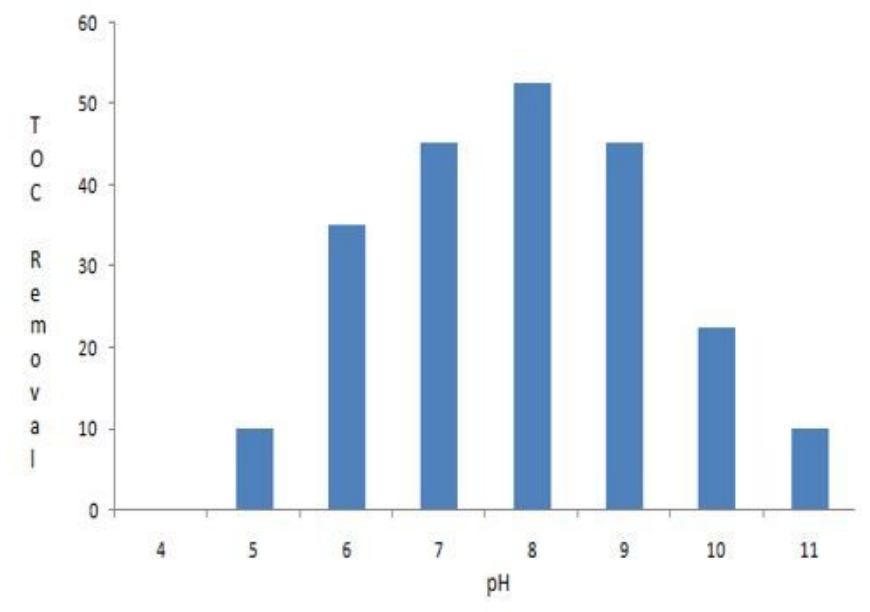

(a)

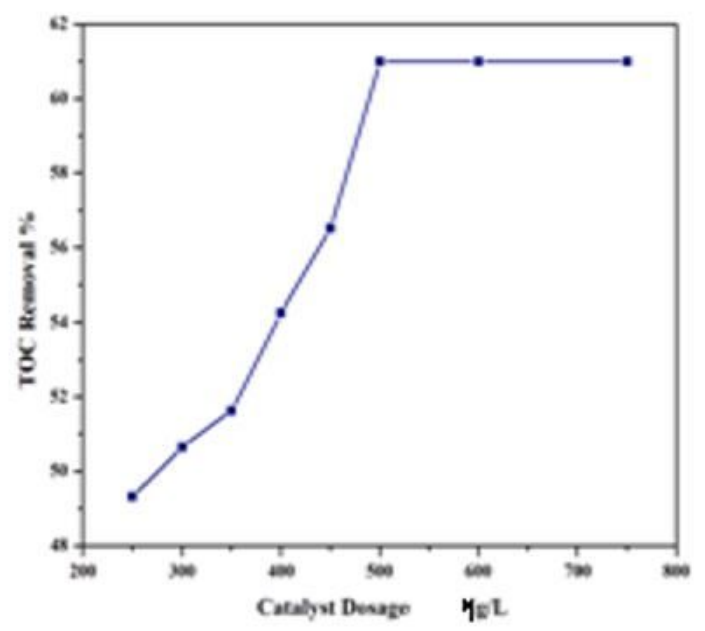

(b)

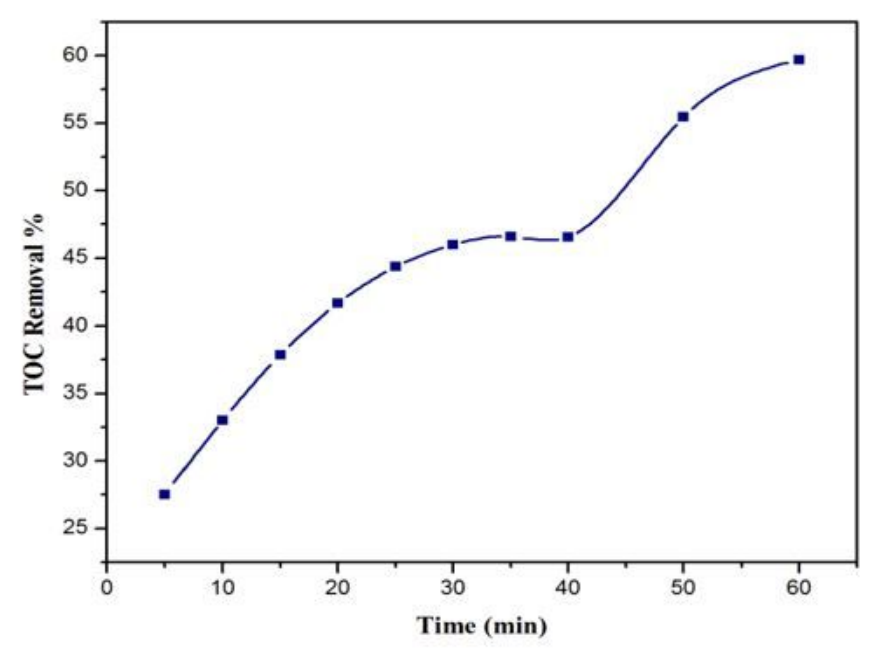

(c)

\section{Figure 5}

Effect of variables on the removal of TOC using catalytic ozonation process;(a) $\mathrm{pH}$ (b) Catalyst dosage and (c) Time. 


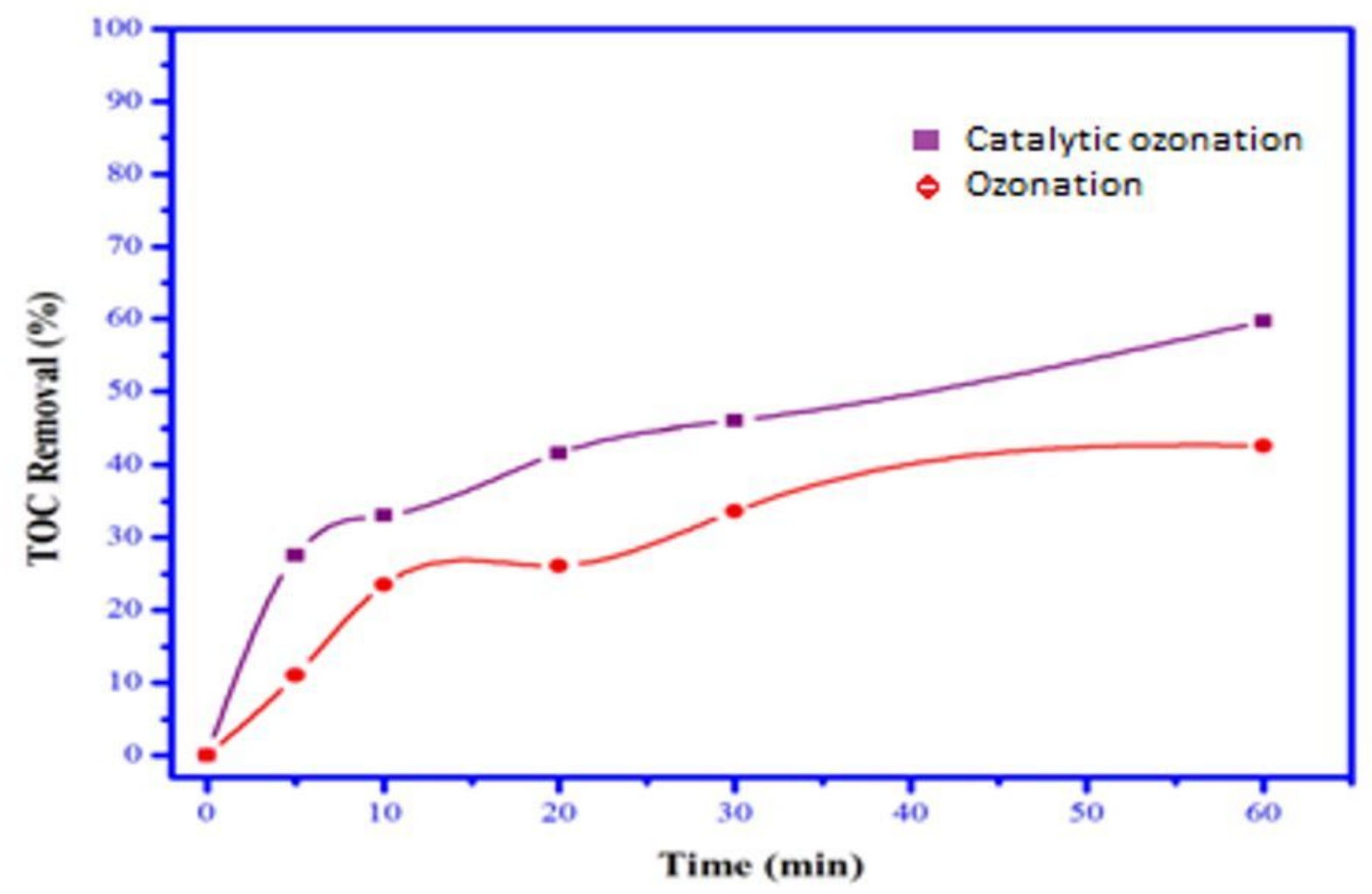

Figure 6

Comparison of TOC removal obtained with catalytic ozonation and non-catalytic ozonation processes at $\mathrm{pH}$ 8, Catalyst dosage $500 \mu \mathrm{g} / \mathrm{L}$ and 60 minutes. 


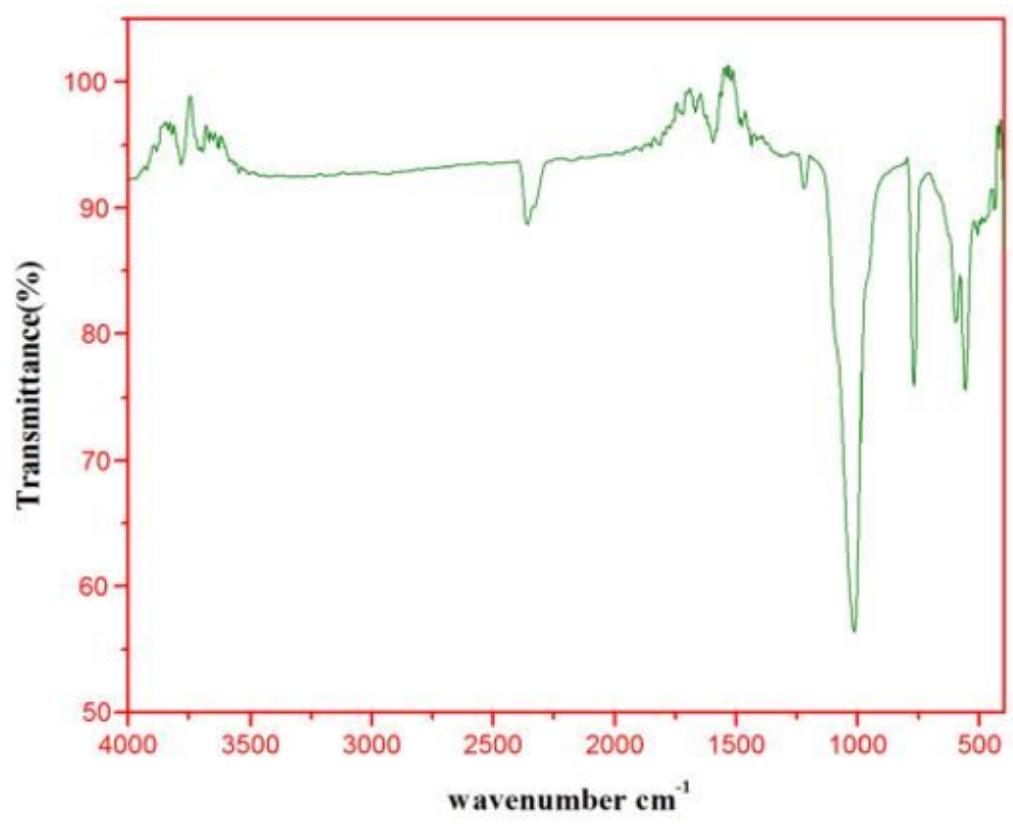

(a)

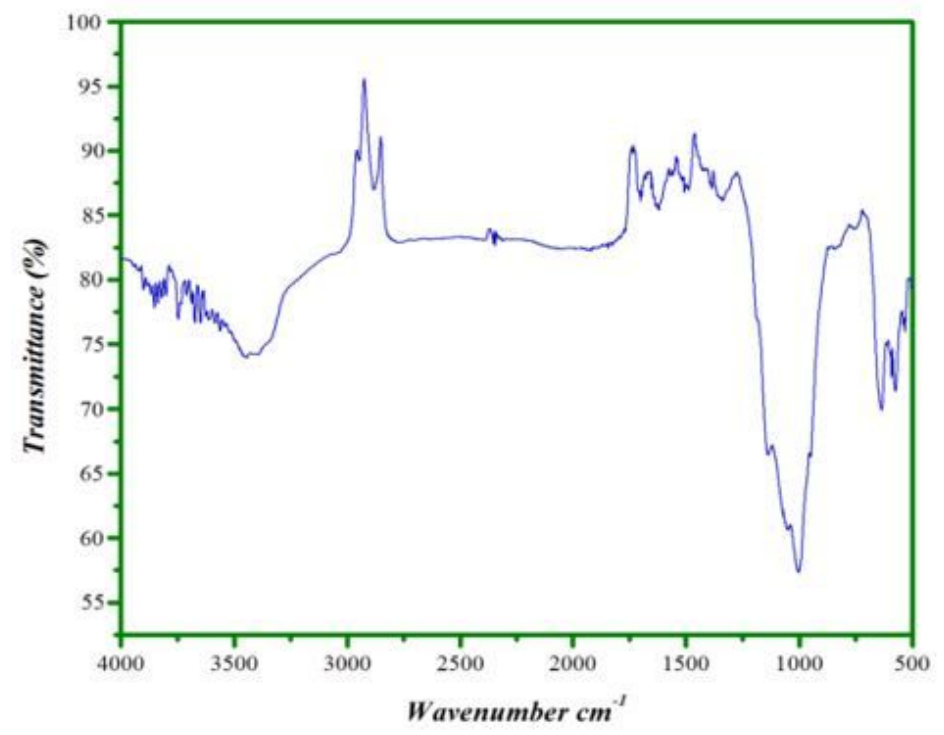

(b)

\section{Figure 7}

FTIR Spectra of AC/CeO2/ZnO nano-composite bimetallic catalyst (a) before and (b) after catalytic ozonation. 


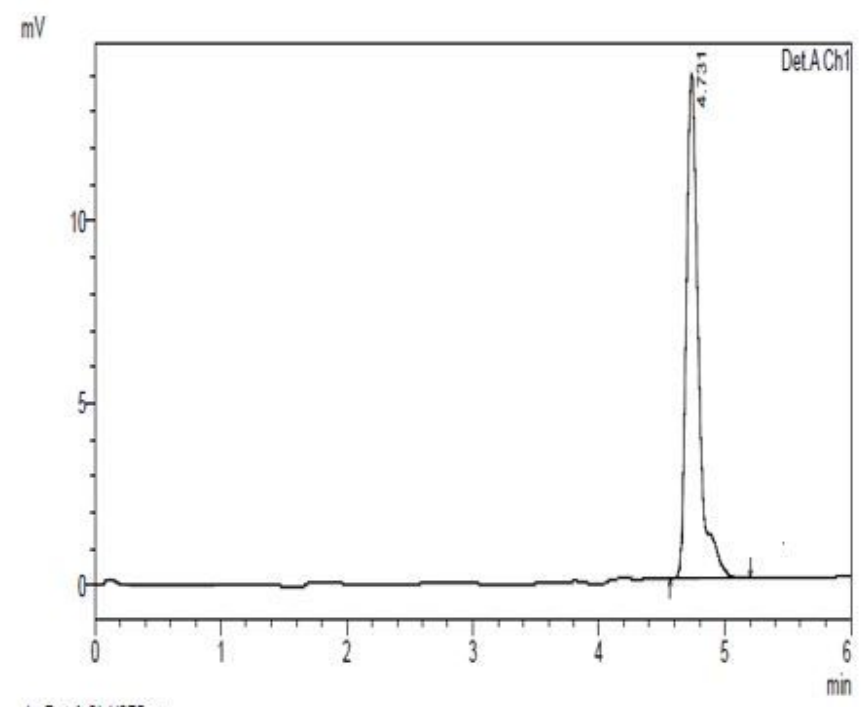

1 DetACh11275nm

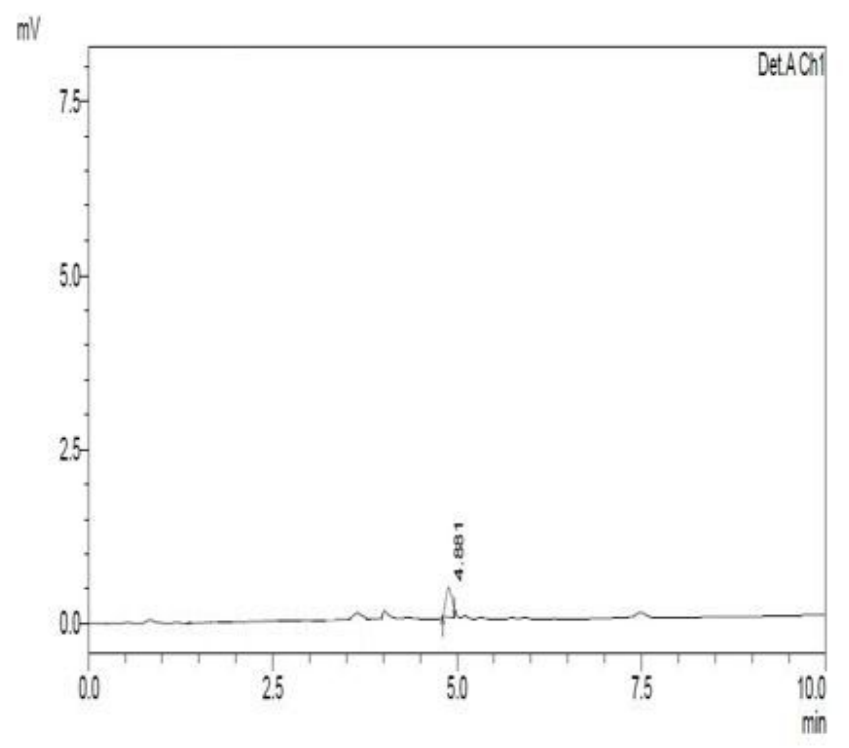

(b)

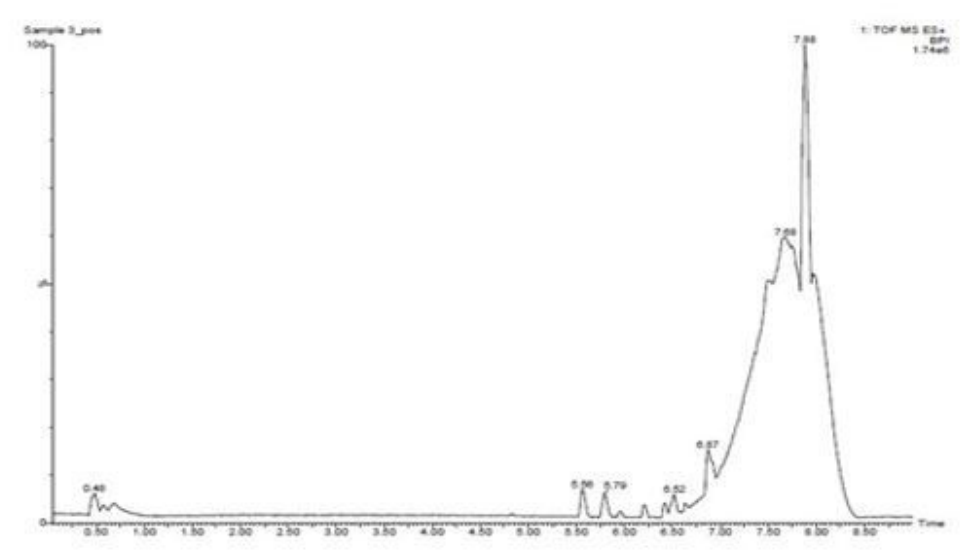

(c)

\section{Figure 8}

HPLC Chromatograms obtained of BPA concentration (a)before (b) after catalytic ozonation and (c) shows the LC-Q-TOF Chromatogram of degradation byproducts 

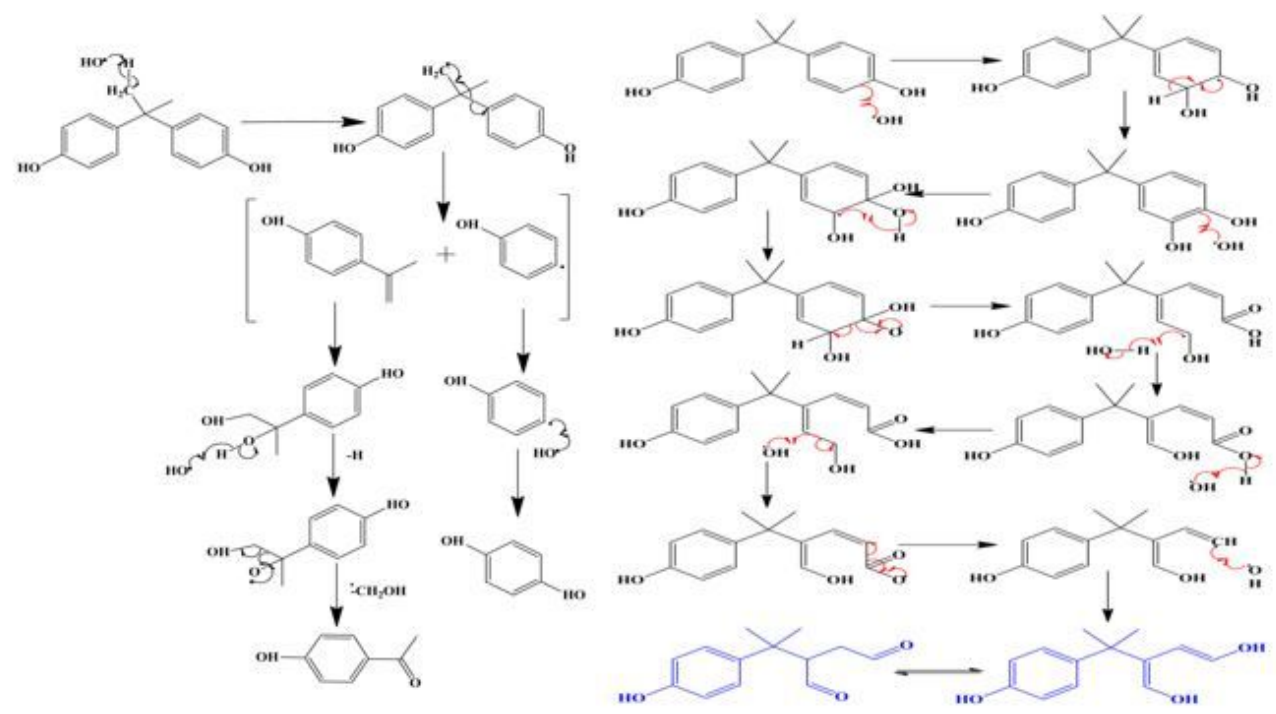

(a)Hydroxyquinone and 4-Hydroxyacetophenone(b)2-(2-(4- Hydroxyphenyl)propan-

2-yl)succinaldehyde

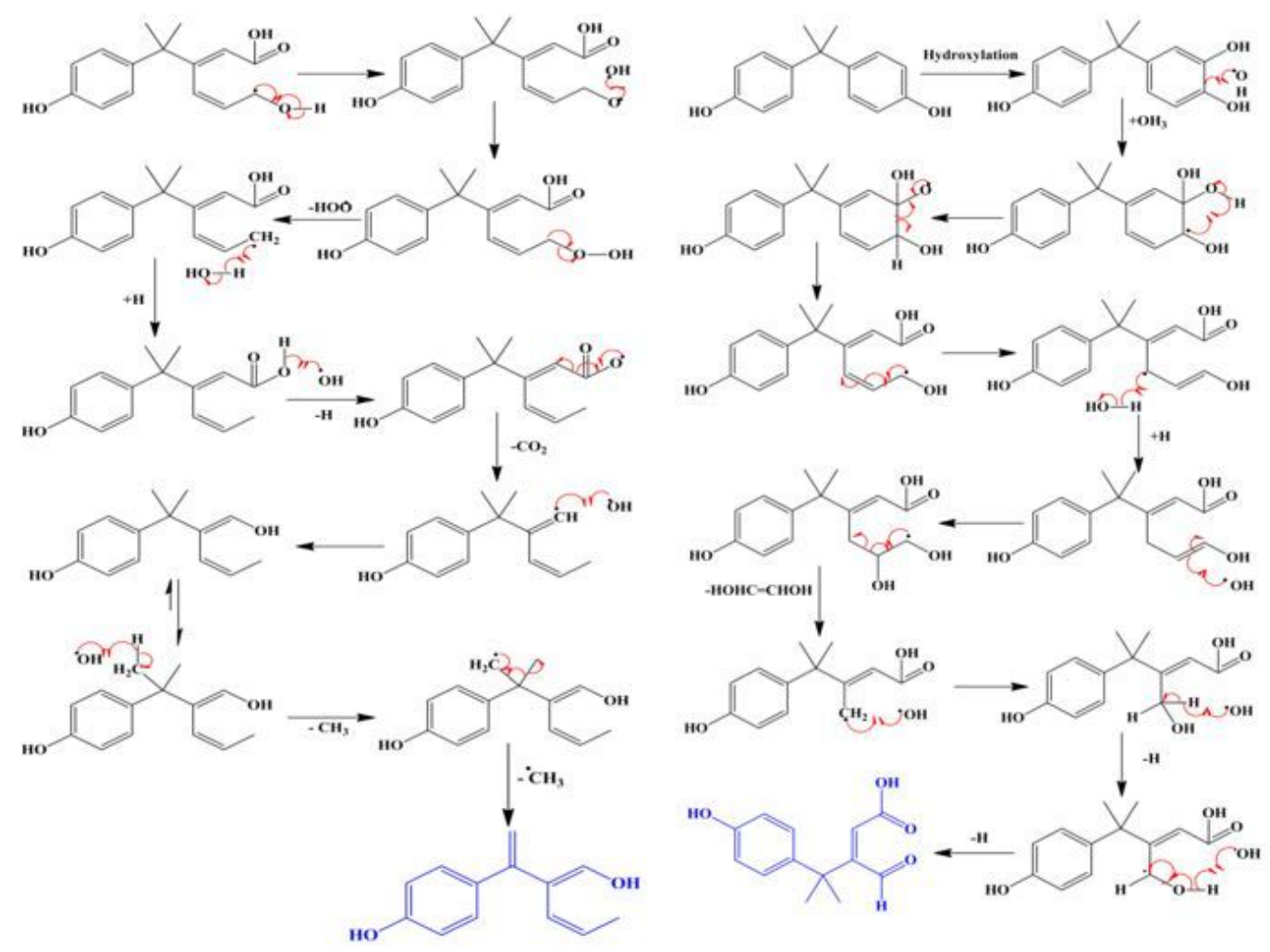

(c)2-(1-(4- Hydroxyphenyl)vinyl)-pent-2-enal(d)3-Formyl-4-(4-hydroxyphenyl)-4methylpent-2-enoic acid

\section{Figure 9}

Proposed pathways for the formation of five aromatic byproducts during catalytic ozonation of BPA

\section{Supplementary Files}

This is a list of supplementary files associated with this preprint. Click to download. 
- Table3.jpg

Page $23 / 23$ 